\title{
Micromobility Station Placement Optimization for a Rural Setting
}

\author{
Taraneh Askarzadeh $(\mathbb{D}$ and Raj Bridgelall \\ Transportation, Logistics \& Finance, College of Business, North Dakota State University, P.O. Box 6050, Fargo, \\ North Dakota 58108-6050, USA \\ Correspondence should be addressed to Raj Bridgelall; raj@bridgelall.com
}

Received 9 July 2021; Revised 7 September 2021; Accepted 18 September 2021; Published 30 September 2021

Academic Editor: Vincent F. Yu

Copyright (C) 2021 Taraneh Askarzadeh and Raj Bridgelall. This is an open access article distributed under the Creative Commons Attribution License, which permits unrestricted use, distribution, and reproduction in any medium, provided the original work is properly cited.

\begin{abstract}
Micromobility is an evolving form of transportation modality that uses small human- or electric-powered vehicles to move people short distances. Planners expected that bike sharing, the first form of micromobility, would reduce traffic congestion, cut travel cost, reduce pollution, enable connectivity with other modes of transport, and promote public health. However, micromobility options also brought new challenges such as the difficulty of placement decisions to encourage adoption and to minimize conflict with other transport modes. Sound deployment decisions depend on the unique environmental characteristics and demographics of a location. Most studies analyzed deployments in high-density urban areas. This research determines the best locations for 5 new bike-sharing stations in Fargo, North Dakota, a small urban area in the rural United States. The workflow combines a geographic information system (GIS), level of traffic stress (LTS) ratings, and location-allocation optimization models. The spatial analysis considered 18 candidate station locations and eliminated those that fell within the 700-meter isochrone walking distance of the 11 existing stations. This case study demonstrates a scalable workflow that planners can repeat to achieve sustainable micromobility deployments by considering the land use, population density, activity points, and characteristics of the available pathways in their unique setting.
\end{abstract}

\section{Introduction}

Transportation planners worldwide view new micromobility options such as bike sharing as another important means towards achieving sustainable transportation [1]. A bike-sharing system (BSS) is a network of bicycles that enable short-distance, low-cost travel for the public. Such services provide short-term rental between self-service stations distributed throughout an area such as a city or suburb [2].

Micromobility services have recently exploded across the world because they provide low-cost, convenient, and accessible alternatives to public transportation. Some studies found that in some cities, micromobility services can result in a mode shift from automobile trips [3]. Additional motivations for deployments include the promotion of physical exercise, congestion reduction, pollution reduction, and support for multimodal transportation connections. Organizations have also deployed dock-less BSSs, but issues such as sidewalk clutter, interference with pedestrian traffic, and increased coordination costs tampered their adoption in many cities [4]. Even with docked BSS, there are numerous challenges to integrating them into communities and the transportation network.

The demand for a BSS can become induced based on the choice of station location. Demand is also closely linked to weather [5], season, and working days. A BSS design scheme that focuses solely on reducing construction costs can lead to unsatisfactory service and high operational costs. Planners also need to balance the important relationship between design to satisfy dynamic demand and design to accommodate supply rebalancing.

Design decisions for rural and small urban areas are different from those of densely populated urban areas and large cities. Most studies previously focused on deployments in large urban areas and large cities. In 2015, the city of Fargo, North Dakota, launched a bike-sharing enterprise with only 11 stations. Expanding the system could increase 
accessibility and reduce the demand for cars in the downtown, shopping, and university districts of this small urban community.

The goal of this study is to identify the most appropriate locations to add new bike-sharing stations in Fargo, North Dakota. The contribution of this study is an analytical workflow that combines level of traffic stress (LTS) network rating, demand location assessment, and spatial optimization models within a geographic information system (GIS) platform to solve the location optimization problem.

The remainder of this paper is organized as follows. Section 2 reviews the body of works related to the case study, demand modeling, LTS formulation, and the spatial optimization problem. Section 3 presents the methodology and further defines the location-allocation optimization problem. Section 4 describes the results and discusses the implications. Section 5 concludes the study and hints at future work.

\section{Literature Review}

Since the introduction of a third-generation BSS in the United States in 2010, the network grew to 3,378 BSSs in 104 cities within six years [6]. Sponsorships and usage fees were the primary sources of funding for BSS deployments in North America [3]. The next subsections describe the case history for the existing bikeshare locations in Fargo, North Dakota, and review related work on general decision making for other BSS deployments.

2.1. Case History. In March 2015, Great Rides Bike Share (GRBS) began operating the first BSS in Fargo, North Dakota, with 11 stations (Figure 1).

After collaborating with North Dakota State University (NDSU) to produce contactless student identification cards, the company distributed 101 bikes across the deployed stations. Consequently, GRBS became the first company in the United States to integrate contactless identification cards with the BSS rental system [7]. As shown in Figure 1, the 11 stations formed two clusters approximately two miles apart. One cluster was on or near the NDSU campus and the other was in and around the Fargo downtown area. The deployment induced a fast growing demand within months, with $79 \%$ and $19 \%$ of the users being students and guests, respectively [7].

2.2. Demand Modeling. The Latent Demand Score (LDS) is a commonly used method of demand analysis for locations where bicycles are not yet a popular option [8]. The LDS method is a probabilistic gravity model that produces a measure of potential demand by considering trip production sites, trip attraction sites, and the bikeable pathways between them. For example, the Portuguese city of Coimbra used the LDS method by considering the number of trips between production and attraction sites and the shortest path between them [9]. The authors later developed an optimization model to maximize demand coverage within a given budget constraint [10].
Market modeling based on other deployments is another method used to forecast demand. For example, New York City identified the three user groups of cyclists based on trends from deployments by Velib' (Paris, France), Velo'v (Grand Lyon, France), and Bicing (Barcelona, Spain) [2]. The analysts then estimated the size of each group (recreational, errand users, and visitors) and their growth based on the adoption rates of 3\%,6\%, and 9\% determined from surveys conducted in London and Paris. Krykewycz et al. [11] identified two market areas in Philadelphia, Pennsylvania, by using a raster-based geographic information system (GIS) method [11]. Based on low-, medium-, and highdemand scenarios from the Grand Lyon and Barcelona surveys, they applied three trip diversion rates to estimate the mode shift for each market.

Gregerson [12] applied the GIS approach used for Philadelphia and the adoption rates observed in Paris and Barcelona to estimate bike-sharing demand for Seattle, Washington, in the United States. Their GIS raster dataset consisted of weighted sum indicators to predict usage. The indicators were population density, non-institutionalized group quarter population density, job density, retail job density, commute trip reduction, tourist attractions, parks, topography, regional transit stations, local transit stops, and various characteristics of the bicycle infrastructure [12].

Daddio [13] created a regression model for bikeshare station demand that was dependent on the trip generation rate, trip attraction rate, and the transportation network characteristics within 400 meters of each station [13]. The author trained the regression model with data from the Capital Bikeshare network in Washington, DC. GarcíaPalomares et al. [14] also proposed a GIS-based method to calculate the spatial distribution of potential trip demand and found that the method can be effectively combined with location-allocation models [14].

2.3. Level of Traffic Stress. The Geelong bike plan team first developed a bicycle tension rate in 1978 to guide deployments in Australian cities [15]. The plan characterized roads based on their difficulty of cycling and the stress of sharing them with other vehicles. Decades later, Sorton and Walsh [16] proposed five bicycle stress levels based on traffic volume, traffic speed, and curb lane width [16]. Mekuria et al. [17] used four levels of traffic stress (LTS) to characterize bikeable paths [17]. The lower stress levels of LTS 1 and LTS 2 were suitable for children and tolerable by most adults, respectively. Murphy and Owen [18] cautioned that restricting bicycles to only low LTS networks can result in a universal reduction in accessibility, modulated by land use [18]. Larsen and ElGeneidy [19] surveyed 2917 cyclists in Montréal, Quebec, Canada, to determine spatial characteristics that affect route choice [19]. They found that cyclists make longer trips on facilities that are separate from vehicle traffic.

Obtaining the street geometry and traffic data for all roads to classify their LTS can be a significant challenge. However, some analysts discovered that OpenStreetMap (OSM) data can provide a viable alternative. For example, Wasserman et al. [20] compared ground-truth data to the 


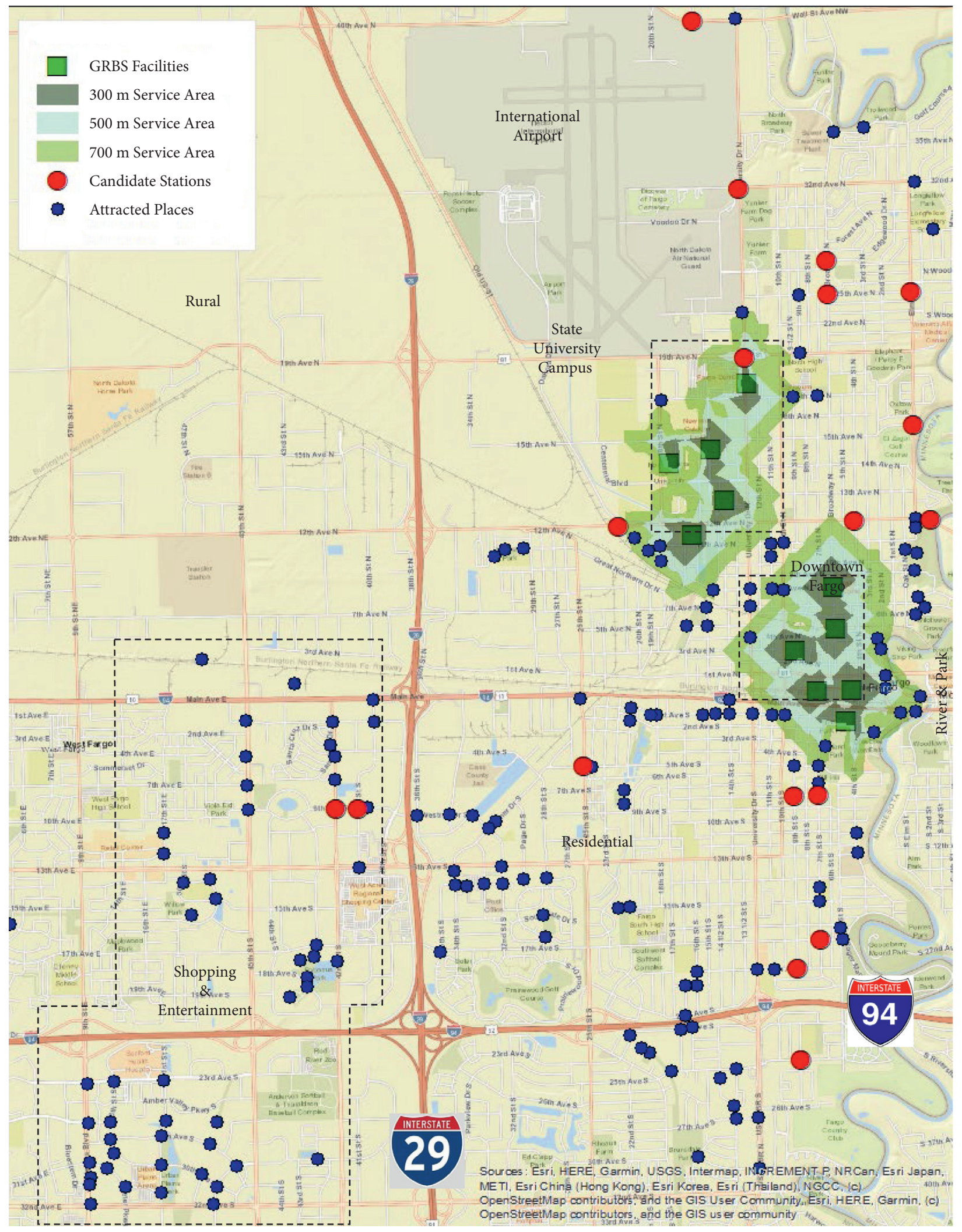

FIgURE 1: Service areas for the GRBS bike stations in Fargo, North Dakota. 
accuracy of LTS predictions based on OSM data and found that the results were comparable but very sensitive to incorrect classifications [20]. Similarly, Hochmair et al. [21] examined the integrity of OSM tags and Google Maps data for bicycle paths and found that the accuracy can surpass those of datasets from local planning agencies [21].

2.4. Location-Allocation Optimization. Common applications of the location-allocation optimization problem are the placement of healthcare facilities [22], fire stations [23], police stations, and schools [24]. The optimization models can define discrete or continuous locations, but planners often use discrete locations in practice [25]. The emergence of GIS presented enhanced options to combine spatial analysis and optimization [26]. Conrow et al. [27] utilized GIS to determine the trade-off between coverage and accessibility for Phoenix, Arizona [27]. Their optimization model selected placements that maximized user coverage for a given level of investment. Guo et al. [28] used a branch and bound optimization algorithm to address the bike-stowage problem for a university campus [28]. Their optimization model solved an impedance minimization problem by considering all pairwise combinations of candidate locations and demand points. Banerjee et al. [29] used a locationallocation model to determine the locations for three new bike stations in Baltimore, Maryland, based on maximizing potential demand and weighing facility locations with a suitability score [29]. More recently, Pérez-Fernández and García-Palomares [30] used a GIS-based location-allocation model to reserve parking spaces for moped-style scooters [30].

\section{Methodology}

The analysis evaluated the placement of five more bikesharing stations in the Fargo small urban area. Figure 2 shows the workflow to prepare the data for the location optimization model to cover all the service points identified.

The workflow is applicable to any populated place, but planners must decide on the candidate station locations and covered activity points (CAPs) based on the population density, land use, trip generation centers, and roadway network characteristics that are unique to every place. The next subsections describe the data sources, service area analysis, LTS formulation, identification of the CAPs, and the location-allocation optimization problem.

3.1. Data and Sources. Table 1 summarizes all the datasets obtained to set up and solve the bikeshare station location optimization problem. The description column identifies the data source.

3.2. Service Area Analysis. A GIS network analysis tool determined accessibility to a facility based on radial walking distances within 700 meters. This distance threshold reflected the accepted transit industry definition for service "catchment" based on a 5-10-minute walk [32]. The service area analysis computed the walking distances along all paths that can access a bike-sharing station. Figure 1 shows the spatial contours of accessibility to each of the 11 existing bike stations. The three contours are the core, primary, and secondary catchment areas based on walking distances of 300,500 , and 700 meters, respectively.

3.3. Level of Traffic Stress. A GIS tool divided the street and bike lane networks in Fargo into small segments for LTS classification. The analysis used roadway geometry and traffic data from METROCOG as inputs to the classification model. Factors included, if present, bike lane width, speed limit, parking width, a residential area indicator, mid-block crossings, the geometry of right-turn lanes, bike lane type, functional class, traffic volume, and the type of intersection signalization. Consequently, a traffic-separated bike lane and a mixed pathway with high traffic volume or high-speed limit had the lowest (LTS 1) and highest (LTS 4) stress levels, respectively. Figure 3 shows a map of the LTS classified roadways of the Fargo study area.

In general, the LTS classification model assigned LTS 1 to physically separated bikeways, multiuse pathways, and walkways in parks and trails. A decision tree model used the same traffic volume, functional class, number of traffic lanes, and speed limit thresholds of Bearn [33] to assign one of four LTS levels to each road segment [33]. In particular, the speed limit thresholds for LTS 1 through LTS 4 were 25, 30, 35, and $50 \mathrm{mph}$, respectively. Bearn [33] scaled down the tiered traffic volume thresholds when considering bikeways that were alongside parking lanes. The model also included geometric criteria used by Mekuria et al. [17] for any auxiliary right lane along the path [17]. The model adopted the LTS level of the highest stress rating among all segments that cross non-signalized intersections.

Figure 3 shows the LTS ratings derived for all bikeable pathways in Fargo. To simplify the methodology and to reduce the scope, the model did not adjust thresholds for signalized intersections to account for possible misalignments between green time and slow riding speeds. Figure 3 shows traffic-separated bikeways (LTS 1) and shared-use pathways (LTS 1 or LTS 2) in different colors to highlight their location and how the network spans the city.

3.4. Candidate Locations. An overlap of four GIS layers helped to identify the candidate locations for bikeshare stations. One layer was the LTS classified network. A second layer was the population density derived from the 2020 block group census data obtained from the U.S. Census Bureau. Selecting areas of high population density assured the potential for demand. A third GIS layer was the land-use classification. Selecting commercial, entertainment, and shopping areas with potentially high trip generation and attraction rates assured potential adoption. A fourth GIS layer was the aggregation of the 700-meter service areas for the existing bikeshare stations. The analyst then identified all junctions with at least three intersecting paths of LTS rating at or below 2. Low-level LTS junctions assured flexible 
accessibility and maximum safety. The analyst then eliminated locations with low population density or poor access to CAPs such as parks, restaurants, and commercial areas. This process resulted in the selection of 18 candidate locations to deploy bikeshare facilities. Figure 3 shows the candidate locations.

3.5. Covered Activity Points. The location-allocation optimization model utilized the METROCOG dataset of 200 covered activity points (CAPs) for Fargo. METROCOG determined the CAPs based on the presence of transit stops, parks, restaurants, bars, commercial areas, industrial centers, universities in highdensity population areas, and surveys of needed coverage points. Planners used the 2020 block group census data from the U.S. Census Bureau to determine the population density of an area smaller than the traffic analysis zones that planners often use in travel demand analysis. Figure 3 shows the location distribution of CAPs across the city. As observed, CAP clusters form near shopping, entertainment, university, park, and residential areas.

3.6. Location-Allocation Optimization. The objective of the location-allocation model was to identify the subset of facilities from among the candidate locations to serve the CAPs with the least travel impedance. Given the multiplicity of alternative routes to a CAP, the analysis simplified the travel impedance as the geodesic distance. The constraint for the model was to select five locations from the 18 candidate sites. The travel cost between a facility location and a CAP was the geodesic distance, with the maximum distance set to 1,000 meters.

The optimization model allowed the same bike station location to service multiple CAPs but restricted more than one station from serving the same CAP. The variables of the optimization problem were as follows:

$I$ : the set of $N$ demand node locations indexed by $i$.

$J$ : the set of $M$ candidate station locations indexed by $j$.

$p$ : the number of stations to deploy.

$w_{i}$ : relative weight of CAP $i$ ( 0 to 2 ).

$d_{i j}$ : the geodesic distance between CAP $i$ and candidate station $j$.

The problem formulation is as follows.

Minimize

$$
D=\sum_{i=1}^{N} \sum_{j=1}^{M} w_{i} d_{i j} Y_{i j}
$$

subject to

$$
\begin{aligned}
& \sum_{j=1}^{M} Y_{i j}=1, \quad \forall i \in I, \\
& \sum_{j=1}^{M} X_{j}=p, \\
& Y_{i j} \leq X_{j}, \quad \forall i \in I, \forall j \in J,
\end{aligned}
$$

where

$$
\begin{aligned}
& Y_{i j}=\left\{\begin{array}{ll}
1 & \text { location } i \text { is served from location } j \\
0 & \text { otherwise }
\end{array}, \quad \forall i \in I, \forall j \in J,\right. \\
& X_{j}=\left\{\begin{array}{ll}
1 & \text { if server is placed at location } j \\
0 & \text { otherwise }
\end{array}, \quad \forall j \in J .\right.
\end{aligned}
$$

The objective function selected candidate sites that minimized the overall weighted geodesic distance in the network. The relative weight for each CAP reflects combined considerations that are important to the planners, for example, social factors and environmental impacts. The nominal weight is 1 . A weight lower or higher than 1 reflects the relative importance level of that CAP. A weight of zero means that the model will not consider service to that CAP. A weight of 2 means that a CAP is $100 \%$ more important than the nominal CAP. A high weight has the effect of a pseudo-increase in the distance to a candidate facility, and hence the optimization for minimum total distance will tend to select a candidate facility that is closer. The planners wanted identical weight for all CAPS in this analysis. The first constraint assured that one and only one station served a demand site. The second constraint assured that the number of stations selected was exactly $p$. The third constraint assured that if the optimizer placed a station at location $j$ to serve location $i$, then it must set station $j$ location as assigned. All decision variables were binary.

\section{Results and Discussion}

Figure 1 shows that Interstates 29 and 94 are the main traffic conduits through Fargo. As anticipated, the LTS model assigned those highways to level 4 as shown in Figure 3. The LTS model also assigned level 4 to the major arterials that form a grid pattern throughout the city. As observed, the LTS model classified local roads in residential areas as LTS 1. Assignments of LTS 2 were mostly to the narrower avenues. The bikeways highlighted are roadways with bike path designations, so the model classified them as LTS 1. Most of the shared-use paths are along the river park to the east of the city. Pedestrians, hikers, and cyclists use the shared-use 


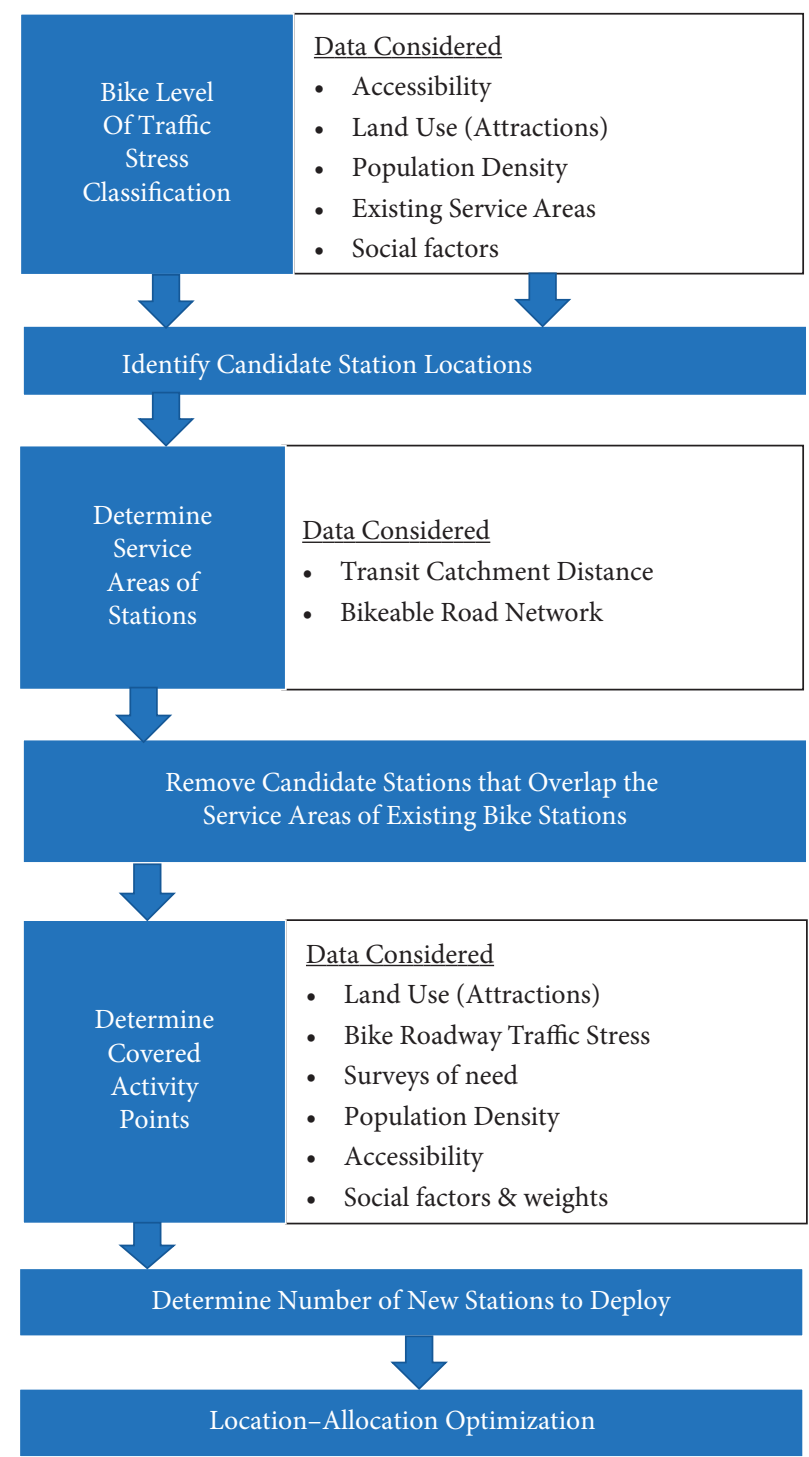

FIgURE 2: Workflow for the location-allocation optimization model.

Table 1: Dataset used for the location optimization problem.

\begin{tabular}{|c|c|}
\hline Dataset & Description \\
\hline $\begin{array}{l}\text { Bike-sharing stations } \\
\text { (existing) }\end{array}$ & $\begin{array}{c}\text { Shapefile from the Fargo-Moorhead Metropolitan Council of Governments (METROCOG) of North Dakota } \\
\text { encoding the location of bike-sharing stations }\end{array}$ \\
\hline Population density & 2020 block group census data from the U.S. Census Bureau \\
\hline Road centerline & $\begin{array}{l}\text { Shapefiles for Fargo street segments from METROCOG including geographical coordinates, number of lanes, } \\
\text { speed limit, functional class, and shape length }\end{array}$ \\
\hline Bikeways & $\begin{array}{c}\text { Shapefiles for Fargo bikeway segments from METROCOG including geographical coordinates, type of } \\
\text { bikeways, and shape length }\end{array}$ \\
\hline Shared-use paths & $\begin{array}{l}\text { Shapefiles for Fargo shared-use path segments from METROCOG including geographical coordinates, } \\
\text { pavement type, pavement width, and shape length }\end{array}$ \\
\hline Traffic signals & Shapefiles for Fargo signalized intersections from METROCOG \\
\hline Traffic volume & METROCOG interactive map of the 2015 annual average daily traffic volume (AADT) for Fargo [31] \\
\hline Right-turn lanes & Manual measurements of right-turn lane geometries from Google Earth ${ }^{\circledR}$ imagery \\
\hline
\end{tabular}

paths, so the model set their LTS ratings to level 1. All candidate bikeshare station locations were at the intersections of traffic-separated bikeways and shared-use pathways, as shown in Figure 3.
The workflow selected the five locations for the new bikesharing stations as shown in Figure 4. Three of the new stations fill gaps within the aggregate service area of the existing stations. The other two extend the service areas towards the 


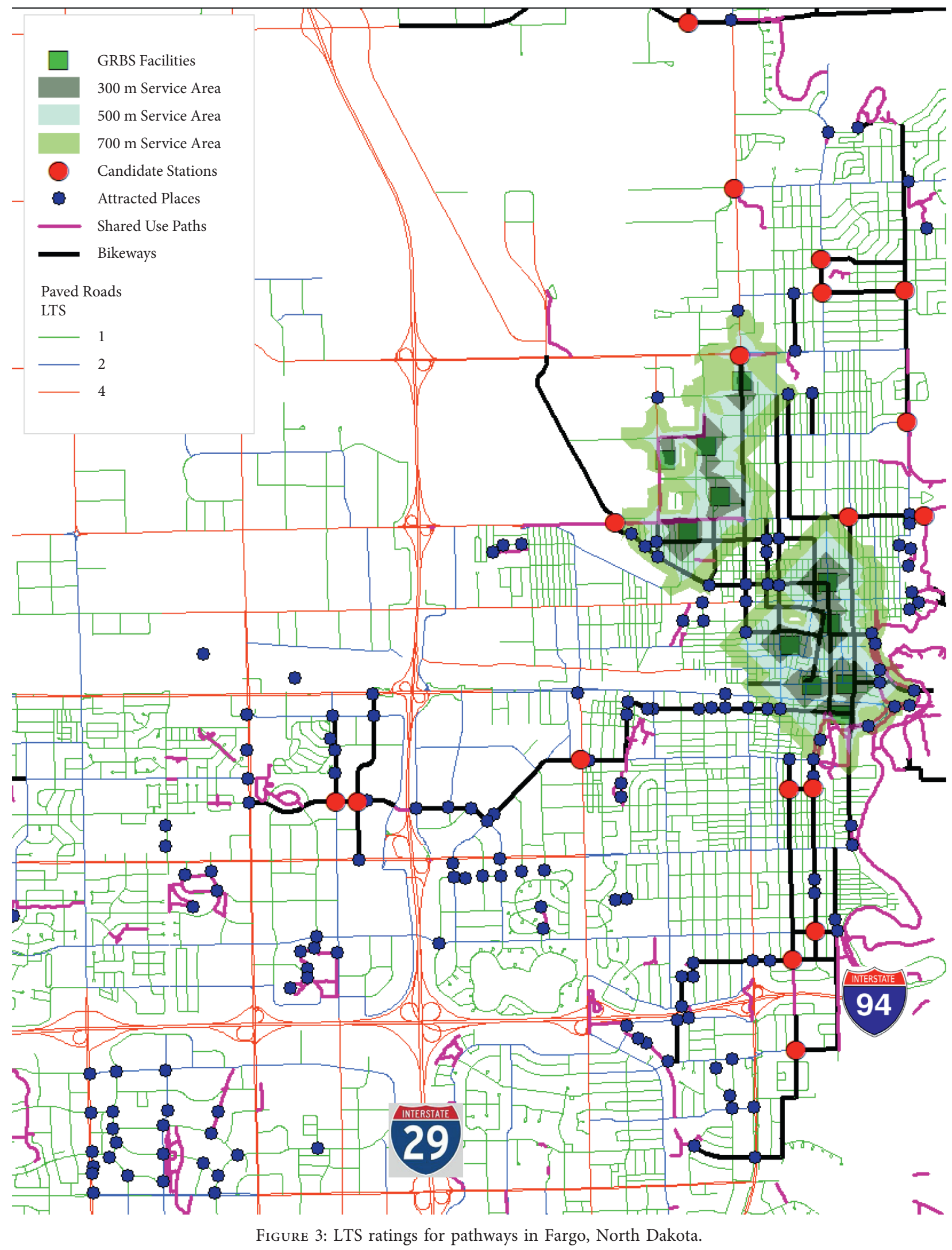




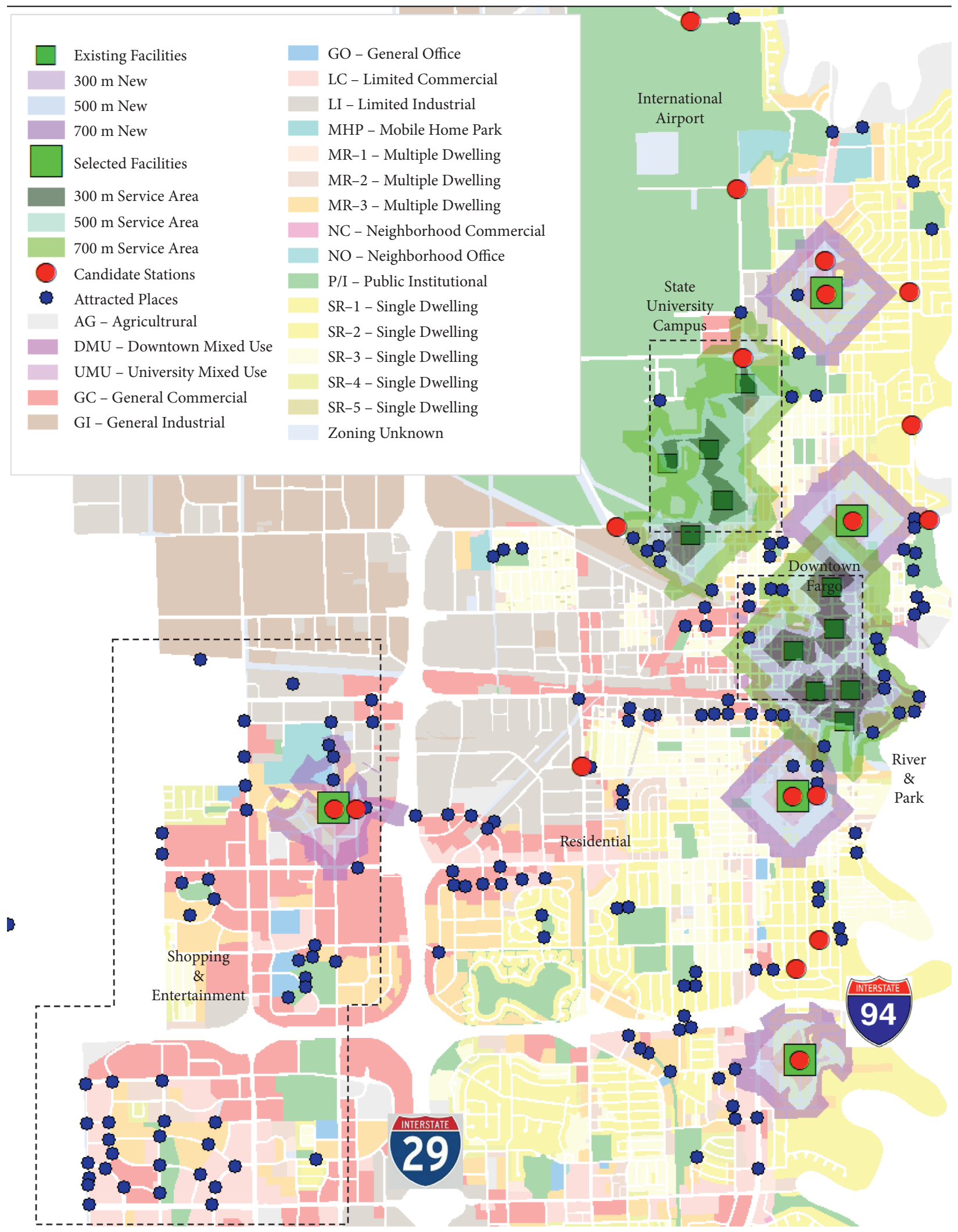

FIgURE 4: Selected facilities and new service areas relative to land-use zoning in the city of Fargo, ND. 
southwestern and southeastern regions of the small urban area. The southwestern location serviced CAPs near shopping and entertainment regions. The southeastern location covers residential, park, and golf course regions. One can visually observe that the selected locations for new stations are distributed in a manner that evenly covers all the CAPs. The coverage was highest in the eastern part of Fargo, along the winding Red River that forms a border between the states of North Dakota and Minnesota. All five of the selected locations are at the intersection of bikeways and shared-use paths, thus making them suitable even for beginners. The 700-meter service areas of the selected locations cover LTS 1 and LTS 2 segments, thus making them easily accessible from many points throughout the city.

\section{Conclusion}

Bike sharing is a popular form of micromobility that is rapidly expanding across many cities of the world to fill mobility gaps and enhance accessibility at affordable prices while achieving sustainable deployments. While there has been a lot of analysis about deployments in high-density areas and cities, analysts have paid little attention to small urban and rural areas. This study addressed the micromobility needs of Fargo, North Dakota, a small urban area in the rural United States. The analysis accounted for the unique land-use settings, street geometry, and traffic situations of the area. Applying the level of traffic stress (LTS) technique to all the available pathways in the area helped identify accessible locations for 18 candidate stations at the junction of low-stress pathways.

The spatial analysis of service areas for the existing bike stations produced isochrones of walking distances based on accepted public transit catchment criteria. Subsequently, overlapping layers in a geographic information system (GIS) helped to identify and eliminate from consideration candidate stations that fell within the isochrone clusters of the existing bikeshare stations. The analysis also determined covered activity points (CAPs) throughout the city based on population density and land-use characteristics such as shopping, entertainment, university, park, and residential areas.

The location-allocation optimization procedure selected the five bike station locations that minimized the total geodesic distances to all the CAPs. Consequently, service area analysis showed that three of the selected locations filled gaps around the existing deployment sites near the state university campus and in the downtown areas. The other two selected locations extended accessibility towards the shopping districts in the southwest and residential areas in the southeast.

Analysts can benefit from this study by following the same workflow. The data obtained for roadway, pathway, intersection, land use, population, and traffic characteristics would be unique to their study area. Analysts can use any suitable GIS tool to visualize the results of their LTS classification and spatial optimization to refine the selection of deployment sites. However, analysts should consider that deployments at the selected sites could lead to an induced demand for bike sharing and other micromobility modes such as electric scooters, which can attract a broader demographic of users. Future work will examine how induced demand would affect the distribution of LTS segments from the current distribution in Fargo. That study will include a traffic impact analysis after collecting data on bicycle volume and motorized traffic volume.

\section{Data Availability}

The shapefile data used to support the findings of this study were supplied by the Fargo-Moorhead Metropolitan Council of Governments (METROCOG) of North Dakota under license and so cannot be made freely available. Requests for access to these data should be made to Dan Farnsworth at 701.532.5106 or farnsworth@fmmetrocog.org.

\section{Conflicts of Interest}

The authors declare that they have no conflicts of interest.

\section{References}

[1] P. Midgley, The Role of Smart Bike-Sharing Systems in Urban Mobility, Global Transport Knowledge Partnership, London, UK, 2009, https://trid.trb.org/view/1152301.

[2] NYC Department of City Planning, Bike-Share Opportunities in New York City, U.S. Department of Transportation, New York, NY, USA, 2009, https://wwwl.nyc.gov/assets/planning/ download/pdf/plans/transportation/bike_share_complete.pdf.

[3] S. Shaheen, E. Martin, A. Cohen, and R. Finson, Public Bikesharing in North America: Early Operator and User Understanding, Mineta Transportation Institute, San Jose, CA, USA, 2012, https://rosap.ntl.bts.gov/view/dot/24566.

[4] A. Rahim Taleqani, C. Vogiatzis, and J. Hough, "Maximum closeness centrality k-clubs: a study of dock-less bike sharing," Journal of Advanced Transportation, vol. 2020, Article ID 1275851, 16 pages, 2020.

[5] R. Godavarthy, J. Mattson, and A. Taleqani, Evaluation Study of the Bike Share Program in Fargo, North Dakota, Upper Great Plains Transportation Institute, Fargo, North Dakota, USA, 2017, https://trid.trb.org/view/1473775.

[6] T. Firestine, "Bike-share stations in the United States," 2016.

[7] R. P. Godavarthy and A. Rahim Taleqani, "Winter bikesharing in US: user willingness, and operator's challenges and best practices," Sustainable Cities and Society, vol. 30, pp. 254-262, 2017.

[8] B. W. Landis, "Bicycle system performance measures," ITEA Journal, vol. 66, no. 2, 1996, https://trid.trb.org/view/459029.

[9] I. Frade and A. Ribeiro, "Bicycle sharing systems demand," Procedia-Social and Behavioral Sciences, vol. 111, pp. 518-527, 2014.

[10] I. Frade and A. Ribeiro, "Bike-sharing stations: a maximal covering location approach," Transportation Research Part A: Policy and Practice, vol. 82, pp. 216-227, 2015.

[11] G. R. Krykewycz, C. M. Puchalsky, J. Rocks, B. Bonnette, and F. Jaskiewicz, "Defining a primary market and estimating demand for major bicycle-sharing program in Philadelphia, Pennsylvania," Transportation Research Record: Journal of the Transportation Research Board, vol. 2143, no. 1, pp. 117-124, 2010.

[12] J. Gregerson, M. Hepp-Buchanan, E. McCormack et al., Seattle Bicycle Share Feasibility Study, University of Washington, Seattle, Washington D. C., USA, 2011, https://nacto.org/wp-content/ uploads/2015/07/2011_McCormack-et-al_Seattle-Bicycle-ShareFeasibility-Study.pdf. 
[13] D. Daddio, Maximizing Bicycle Sharing: An Empirical Analysis of Capital Bikeshare usage, University of North Carolina, Chapel Hill, NC, USA, 2012.

[14] J. CarlosGarcía, P. G. Javier, and M. Latorre, “Optimizing the location of stations in bike-sharing programs: a GIS approach," Applied Geography, vol. 35, pp. 235-246, 2012.

[15] M. Scott, D. D. Hurnall, and W. H. Pattinson, The Geelong Bikeplan: Practical Planning for Cyclists Real Needs, Western Australia Director General of Transport, Perth, Australia, 1978, https://trid.trb.org/view/79790.

[16] A. Sorton and T. Walsh, "Conclusions," Bicycle Transportation, vol. 1438, pp. 17-24, 1994.

[17] M. Mekuria, P. Furth, and H. Nixon, Low-Stress Bicycling and Network Connectivity, Mineta Transportation Institute, San Jose, CA, USA, 2012, https://rosap.ntl.bts.gov/view/dot/ 24453.

[18] B. Murphy and A. Owen, "Implementing low-stress bicycle routing in national accessibility evaluation," Transportation Research Record: Journal of the Transportation Research Board, vol. 2673, no. 5, pp. 240-249, 2019.

[19] J. Larsen and A. El-Geneidy, "A travel behavior analysis of urban cycling facilities in Montréal, Canada," Transportation Research Part D: Transport and Environment, Transportation Research Part D: Transport and Environment, vol. 16, no. 2, pp. 172-177, 2011.

[20] D. Wasserman, A. Rixey, X. Zhou, D. Levitt, and M. Benjamin, "Evaluating OpenStreetMap's performance potential for level of traffic stress analysis," Transportation Research Record: Journal of the Transportation Research Board, vol. 2673, no. 4, pp. 284-294, 2019.

[21] H. H. Hochmair, D. Zielstra, and P. Neis, "Assessing the completeness of bicycle trail and lane features in OpenStreetMap for the United States," Transactions in GIS, vol. 19, no. 1, pp. 63-81, 2015.

[22] L. Murawski and R. L. Church, "Improving accessibility to rural health services: the maximal covering network improvement problem," Socio-Economic Planning Sciences, vol. 43, no. 2, pp. 102-110, 2009.

[23] N. Liu, B. Huang, and M. Chandramouli, "Optimal siting of fire stations using GIS and ANT algorithm," Journal of Computing in Civil Engineering, vol. 20, no. 5, pp. 361-369, 2006.

[24] J. C. Teixeira and A. P. Antunes, "A hierarchical location model for public facility planning," European Journal of Operational Research, vol. 185, no. 1, pp. 92-104, 2008.

[25] A. G.-O. Yeh and M. H. Chow, "An integrated GIS and location-allocation approach to public facilities planning-an example of open space planning," Computers, Environment and Urban Systems, vol. 20, no. 4-5, pp. 339-350, 1996.

[26] A. Ribeiro and A. P. Antunes, "A GIS-based decision-support tool for public facility planning," Environment and Planning B: Planning and Design, vol. 29, no. 4, pp. 553-569, 2002.

[27] L. Conrow, A. T. Murray, and H. A. Fischer, "An optimization approach for equitable bicycle share station siting," Journal of Transport Geography, vol. 69, pp. 163-170, 2018.

[28] T. Guo, J. Yang, L. He, and K. Tang, "Layout optimization of campus bike-sharing parking spots," Journal of Advanced Transportation, vol. 2020, Article ID 8894119, 10 pages, 2020.

[29] S. Banerjee, M. M. Kabir, N. K. Khadem, and C. Chavis, "Optimal locations for bikeshare stations: a new GIS based spatial approach," Transportation Research Interdisciplinary Perspectives, vol. 4, Article ID 100101, 2020.

[30] O. Pérez-Fernández and J. C. García-Palomares, "Parking places to moped-style scooter sharing services using GIS location-allocation models and GPS data," ISPRS International Journal of Geo-Information, vol. 10, no. 4, p. 230, 2021.

[31] METROCOG, Traffic Counts, Fargo-Moorhead Metropolitan Council of Governments (METROCOG), Bridgeport, CT, USA, 2021, http://fmmetrocog.org/resources/traffic-counts.

[32] FTA, Transit-Oriented Development and Joint Development in the United States: A Literature Review, Federal Transit Administration (FRA), Washington, DC, USA, 2002, http:// onlinepubs.trb.org/onlinepubs/tcrp/tcrp_rrd_52.pdf.

[33] C. Bearn, C. Mingus, and K. Watkins, "An adaption of the level of traffic stress based on evidence from the literature and widely available data," Research in Transportation Business \& Management, vol. 29, pp. 50-62, 2018. 